\title{
Crystal structure of crystal structure of tetrakis(thiourea)cadmium tetrakis(thiocyanato)zincate, $\left[\mathrm{Cd}\left(\mathrm{NH}_{2} \mathrm{CSNH}_{2}\right)_{4}\right]\left[\mathrm{Zn}(\mathrm{SCN})_{4}\right]$
}

\author{
X. N. Jiang*, W. T. Yu, D. Xu, D. R. Yuan, M. K. Lu, S. Y. Guo, F. Q. Meng, G. H. Zhang, X. Q. Wang \\ and M. H. Jiang \\ Shandong University, Institute of Crystal Materials, State Key Laboratory of Crystal Materials, Jinan 250100, Peoples Republic of China
}

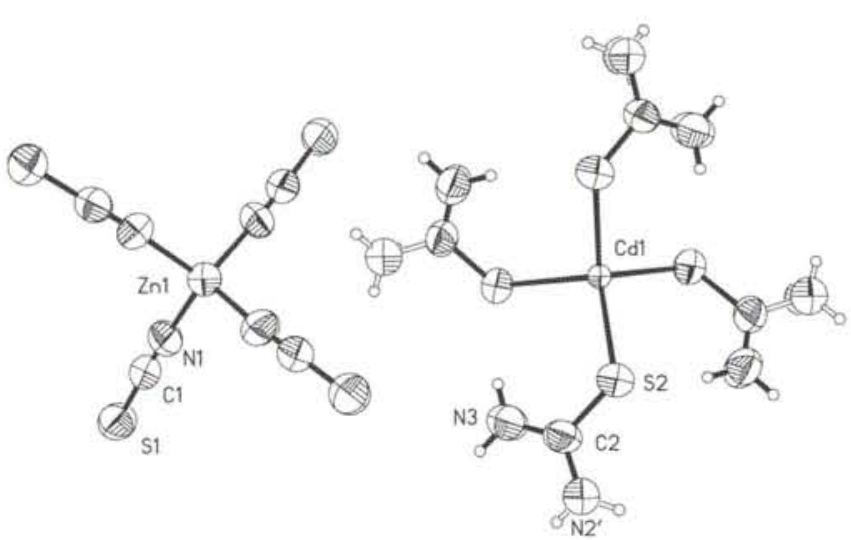

\begin{abstract}
$\mathrm{C}_{8} \mathrm{H}_{16} \mathrm{CdN}_{12} \mathrm{~S}_{8} \mathrm{Zn}$, tetragonal, $\bar{l} \overline{4}$ (No. 82), $a=17.258(2) \AA$, $c=4.2647(7) \AA, V=1270.1 \AA^{3}, Z=2, R_{\mathrm{gt}}(F)=0.069$, $w R_{\text {ref }}\left(F^{2}\right)=0.186, T=293 \mathrm{~K}$.
\end{abstract}

\section{Source of material}

The title compound was synthesized by the reaction of zinc chloride, cadmium chloride, potassium thiocyanate and thiourea in stoichiometric amounts at about $313 \mathrm{~K}$ in water. The mother solution after synthesis was kept at $323 \mathrm{~K}$ for one day and the transparent single crystals were obtained.

\section{Discussion}

In recent years, much attention has been paid to the research of novel, high-quality nonlinear optical (NLO) crystals, especially those metalorganic or semiorganic complex crystals, which combine the advantages of inorganic crystals, such as good stability, with the advantages of organic crystals, such as high nonlinearity, and can generate high efficient second-harmonic blue-violet light using GaAlAs laser diodes. In order to find this type of crystals, much work has been done on the complex crystals of $\mathrm{MM}^{\prime}(\mathrm{SCN})_{4}$ and $\mathrm{MM}^{\prime}(\mathrm{SCN})_{4} \cdot \mathrm{nL}$, where $\mathrm{M}=\mathrm{Zn}, \mathrm{Cd}, \mathrm{Mn} ; \mathrm{M}^{\prime}=\mathrm{Cd}, \mathrm{Hg}$ and $\mathrm{L}=$ adducts $[1-10]$. The synthesis, crystal structure and properties of zinc cadmium thiocyanate (ZCTC) has been reported $[2,6]$. As part of continuous work, we report here the structure and properties of tetrakis(thiourea)cadmium tetrakis(thiocyanato)zincate (TCTZ).
Thiocyanate ions can bind to metal ions through either $\mathrm{S}$ or $\mathrm{N}$. Thiourea $\left(\mathrm{NH}_{2} \mathrm{CSNH}_{2}\right.$, tu) is also a bidentate ligand with a sulphur or nitrogen as potential electron donor. According to the Hard and Soft Acids and Bases (HSAN) concept [11], the different types of binding to $\mathrm{SCN}$ or thiourea depend on the hardness of metal ions. Therefore, the hard $\mathrm{Zn}$ binds through the hard $\mathrm{N}$ atom while $\mathrm{Cd}$ can bind through either $\mathrm{N}$ or $\mathrm{S}$ atoms because the hardness of $\mathrm{Cd}$ is just between the hard $\mathrm{Zn}$ and soft $\mathrm{Hg}$. In the crystal TCTZ, the $\mathrm{Zn}$ ions are surrounded tetrahedrally by four $\mathrm{N}$ atoms of the thiocyanates, with a $\mathrm{Zn}-\mathrm{N}$ bond distance of $2.0242 \AA$ and angles of $107.18^{\circ}$ and $114.15^{\circ}$, while the $\mathrm{Cd}$ ions are surrounded by four $\mathrm{S}$ atoms of the thiourea ligands, with a $\mathrm{Cd}-\mathrm{S}$ bond distance of $2.5702 \AA$ and angles of $107.35^{\circ}$ and $113.81^{\circ}$, forming seperated $\left[\mathrm{Zn}(\mathrm{NCS})_{4}\right]^{2-}$ and $\left[\mathrm{Cd}\left(\mathrm{NH}_{2} \mathrm{CSNH}_{2}\right)_{4}\right]^{2+}$ tetrahedral structures, respectively. In ZCTC, however, the $-\mathrm{S}=\mathrm{C}=\mathrm{N}$ - act as bridges linking $\mathrm{ZnN}_{4}$ and $\mathrm{CdS}_{4}$ tetrahedra into infinite three-dimensional network. The $\mathrm{Cl}-\mathrm{N} 1$ and $\mathrm{S} 1-\mathrm{Cl}$ bond distances $(1.0722 \AA$ and $1.6506 \AA$,respectively)are slightly shorter than those in ZCTC (1.153(6) $\AA$ and 1.651(5) $\AA$, respectively), because $\mathrm{SCN}^{-}$acts as monodentate ligand through $\mathrm{N}$ atom in TCTZ while as bidentate ligand in ZCTC. From the bonds and angles, it is obvious that the structure of ZCTC - 4tu consists of slightly flattened $\left[\mathrm{Zn}(\mathrm{NCS})_{4}\right]^{2-}$ and $\left[\mathrm{Cd}\left(\mathrm{NH}_{2} \mathrm{CSNH}_{2}\right)_{4}\right]^{2+}$ tetrahedraal units, which are connected by the hydrogen bonds between the $\mathrm{H}$ atoms of the thioureas and the $\mathrm{S}$ atoms of the neighboring thiocyanates, forming three-dimensional framwork. The central $\mathrm{Zn}$ and $\mathrm{Cd}$ atoms of the tetrahedra are located on 4 inversion point. The macroscopic nonlinear susceptibility of TCTZ may be related to the microscopic hyperpolarisabilities of the dipolar thiocyanate ions and the distorted tetrahedra. The second harmonic generation (SHG) effect of the crystal was determined. It was found that the TCTZ crystal is comparable with ZCTC crystal in the SHG effects.

Table 1. Data collection and handling.

$\begin{array}{ll}\text { Crystal: } & \begin{array}{l}\text { colourless neddle, } \\ \text { size } 0.15 \times 0.18 \times 0.25 \mathrm{~mm}\end{array} \\ & \text { Mo } K_{\alpha} \text { radiation }(0.71073 \AA) \\ \text { Wavelength: } & 24.62 \mathrm{~cm}^{-1} \\ \mu: & \text { Bruker P4, } \theta / 2 \theta \\ \text { Diffractometer, scan mode: } & 60^{\circ} \\ 2 \theta_{\text {max }}: & 1445,1339 \\ N(h k l)_{\text {measured }}, N(h k l)_{\text {unique }}: & I_{\text {obs }}>2 \sigma\left(l_{\text {obs }}\right), 1259 \\ \text { Criterion for } I_{\text {obs }}, N(h k l)_{\text {gt }}: & 69 \\ N(\text { param })_{\text {refined: }} & \text { SHELXTL [12] }\end{array}$


Table 2. Atomic coordinates and displacement parameters (in $\AA^{2}$ ).

\begin{tabular}{lllllll}
\hline Atom & Site & Occ. & $x$ & $y$ & $z$ & $U_{\text {iso }}$ \\
\hline $\mathrm{H}(3 \mathrm{~A})$ & $8 g$ & & $0.1329(8)$ & $0.3684(9)$ & $0.283(6)$ & 0.113 \\
$\mathrm{H}(3 \mathrm{~B})$ & $8 g$ & & $0.2172(8)$ & $0.3559(9)$ & $0.229(6)$ & 0.113 \\
$\mathrm{~N}\left(2^{\prime}\right)$ & $8 g$ & $0.4(2)$ & $0.264(2)$ & $0.470(2)$ & $0.55(2)$ & $0.05(1)$ \\
$\mathrm{H}\left(2^{\prime} \mathrm{A}\right)$ & $8 g$ & 0.4 & $0.302(2)$ & $0.438(2)$ & $0.54(2)$ & 0.064
\end{tabular}

Table 2. Continued

\begin{tabular}{lllllll}
\hline Atom & Site & Occ. & $x$ & $y$ & $z$ & $U_{\text {iso }}$ \\
\hline $\mathrm{H}\left(2^{\prime} \mathrm{B}\right)$ & $8 g$ & 0.4 & $0.271(2)$ & $0.515(2)$ & $0.63(2)$ & 0.064 \\
$\mathrm{~N}(2)$ & $8 g$ & 0.6 & $0.268(2)$ & $0.473(2)$ & $0.44(2)$ & $0.070(9)$ \\
$\mathrm{H}(2 \mathrm{~A})$ & $8 g$ & 0.6 & $0.304(2)$ & $0.444(2)$ & $0.37(2)$ & 0.084 \\
$\mathrm{H}(2 \mathrm{~B})$ & $8 g$ & 0.6 & $0.280(2)$ & $0.516(2)$ & $0.53(2)$ & 0.084
\end{tabular}

Table 3. Atomic coordinates and displacement parameters (in $\AA^{2}$ ).

\begin{tabular}{|c|c|c|c|c|c|c|c|c|c|c|}
\hline Atom & Site & $x$ & $y$ & $z$ & $U_{11}$ & $U_{22}$ & $U_{33}$ & $U_{12}$ & $U_{13}$ & $U_{23}$ \\
\hline $\mathrm{Cd}(1)$ & $2 c$ & 0 & $1 / 2$ & $1 / 4$ & $0.0271(4)$ & $U_{11}$ & $0.0473(7)$ & 0 & 0 & 0 \\
\hline $\mathrm{Zn}(1)$ & $2 a$ & 0 & 0 & 0 & $0.057(1)$ & $U_{11}$ & $0.093(2)$ & 0 & 0 & 0 \\
\hline$C(1)$ & $8 g$ & $0.1231(9)$ & $0.0926(9)$ & $0.370(5)$ & $0.064(7)$ & $0.058(6)$ & $0.10(1)$ & $0.005(6)$ & $0.002(7)$ & $0.006(7)$ \\
\hline$C(2)$ & $8 g$ & $0.1951(8)$ & $0.4504(9)$ & $0.430(4)$ & $0.051(6)$ & $0.067(7)$ & $0.09(1)$ & $0.005(5)$ & $0.005(6)$ & $0.015(7)$ \\
\hline$N(1)$ & $8 g$ & $0.0772(7)$ & $0.0608(6)$ & $0.260(7)$ & $0.067(5)$ & $0.062(5)$ & $0.095(8)$ & $0.010(4)$ & $0.01(1)$ & $0.00(1)$ \\
\hline $\mathrm{N}(3)$ & $8 g$ & $0.1801(8)$ & $0.3841(9)$ & $0.299(6)$ & $0.062(6)$ & $0.081(7)$ & $0.14(2)$ & $0.010(5)$ & $0.01(1)$ & $0.04(1)$ \\
\hline
\end{tabular}

Acknowledgments. This work has been supported by the National Natural Science Foundation of China (No. 69890230 and No. 69778023) and the Scientific Research Foundation for Outstanding Young Scientist of Shandong Province of China.

\section{References}

1. Xu, D.; Yu, W. T.; Wang, X. Q.; Yuan, D. R.; Lu, M. K.; Yang, P.; Guo, S. Y.; Meng, F. Q.; Jiang, M.H.: Zinc mercury thiocyanate (ZMTC). Acta Crystallogr. C55 (1999) 1203-1205.

2. Tian, Y.P.; Yu, W. T.; Fang, Q.; Wang, X. Q.; Yuan, D. R.; Xu, D.; Jiang, M. H.: Zinc cadmium thiocyanate (ZCTC). Acta Crystallogr. C55 (1999) 1393-1395.

3. Yuan, D. R.; Xu, D.; Liu, M. G.; Fang, Q.; Yu, W. T.; Hou, W. B.; Bing, Y. H.; Sun, S. Y.; Jiang, M. H.: Structure and properties of a complex crystal for laser diode frequency doubling: Cadmium mercury thiocyanate. Appl. Phys. Lett. 70 (1997) 544-546.

4. Yuan, D. R.; Zhong Z. W.; Liu, M. G.; Xu, D.; Fang, Q.; Bing, Y. H.; Sun, S. Y.; Jiang, M. H.: Growth of cadmium mercury thiocyanate single crystal for laser diode frequency doubling. J. Cryst. Growth 186 (1998) 240-244.

5. Yan, Y. X.; Fang, Q.; Yu, W. T.; Yuan, D. R.; Tian, Y. P.; Jiang, M. H.; Williams, I. D.; Cai, Z. G.: Synthesis, structure and nonlinear optical properties of Iron Mercury Thiocyanate $\left(\mathrm{FeHg}(\mathrm{SCN})_{4}\right)$ and Manganese Mercury Thiocyanate $\left(\mathrm{MnHg}(\mathrm{SCN})_{4}\right)$. Acta Chim. Sinica 57 (1999) $1257-1261$.
6. Wang, X. Q.; Xu, D.; Yuan, D. R.; Tian, Y. P.; Yu, W. T. L.; Sun, S. Y.; Yang, Z. H.; Fang, Q.; Lu, M. K.; Yan, Y. X.; Meng, F. Q.; Guo, S. Y.; Zhang, G. H.; Jiang, M. H.: Synthesis, structure and properties of a new nonlinear optical material: Zinc Cadmium Tetrathiocyanate. Mater. Res. Bull. 34 (1999) 2003-2011.

7. Wang, X. Q.; Yu, W. T.; Xu, D.; Lu, M. K.; Yuan, D. R.: Polylbis(dimethyl-sulfoxide- $\mathrm{\kappa} O)$ tris(- $\mathrm{\kappa} N$ ) manganese]- $\mu$-thiocyanato- $\kappa^{2} N: S$-mercury]. Acta Crystallogr. C56 (2000) 418-420.

8. Guo, S. Y.; Xu, D.; Yuan, D. R.; Yang, Z. H.; Zhang, G. H.; Sun, S. Y.; Wang, X. Q.; Zhou, M.; Jiang, M. H.: A novel organometallic nonlinear optical complex crystal: Cadmium mercury thiocyanate dimethylsulphoxide. Science \& Technology of Artificial Crystals, 2000 (accepted).

9. Guo, S. Y.; Yuan, D. R.; Xu, D.; Zhang, G. H.; Sun, S. Y.; Meng, F. Q.; Wang, X. Q.; Jiang, X. N.; Jiang, M. H.: Growth of cadmium mercury thiocyanate dimethy sulphoxide single crystal for laser frequency doubling. Science \& Technology of Artificial Crystals, 2000 (accepted).

10. Zhou, M.; Yu, W. T.; Xu, D.; Guo, S.Y.; Lu, M. K.; Yuan, D. R.: Crystal structure of cadmium mercury tetrathiocyanate (glycol monomethyl ether), $\mathrm{C}_{7} \mathrm{H}_{8} \mathrm{CdHgO}_{2} \mathrm{~S}_{4}$. Z Kristallogr. NCS 215 (2000) 425-426.

11. Fukushima, N.; Waizumi, K.: Chem. Express 8 (1993) 269.

12. Bruker: SHELXTL. Structure determination programs. Version 5.1, Bruker AXS, Inc, Madison, Wisconsin, USA 1997. 